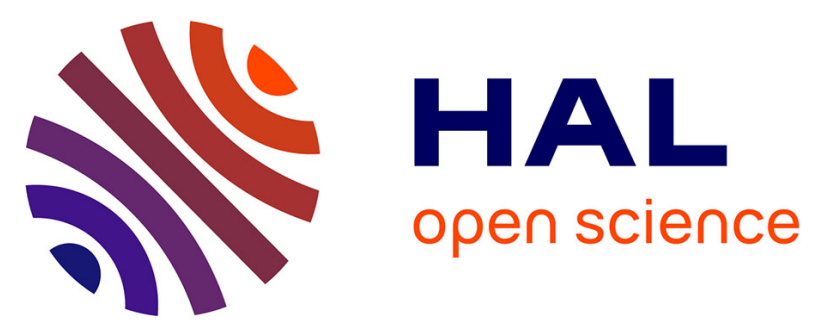

\title{
Kinetics aspects, rheological properties and mechanoelectrical effects of hydrogels composed of polyacrylamide and polystyrene nanoparticles.
}

Caroline Thévenot, Abdel Khoukh, Stephanie Reynaud, Jacques Desbrieres, Bruno Grassl

\section{To cite this version:}

Caroline Thévenot, Abdel Khoukh, Stephanie Reynaud, Jacques Desbrieres, Bruno Grassl. Kinetics aspects, rheological properties and mechanoelectrical effects of hydrogels composed of polyacrylamide and polystyrene nanoparticles.. Soft Matter, 2006, 3, pp.437-447. 10.1039/b614166h . hal-00469606

\section{HAL Id: hal-00469606 https://hal.science/hal-00469606}

Submitted on 1 Apr 2010

HAL is a multi-disciplinary open access archive for the deposit and dissemination of scientific research documents, whether they are published or not. The documents may come from teaching and research institutions in France or abroad, or from public or private research centers.
L'archive ouverte pluridisciplinaire HAL, est destinée au dépôt et à la diffusion de documents scientifiques de niveau recherche, publiés ou non, émanant des établissements d'enseignement et de recherche français ou étrangers, des laboratoires publics ou privés. 


\section{Kinetics aspects, rheological properties and}

\section{mechanoelectrical effects of hydrogels composed}

\section{of polyacrylamide and polystyrene nanoparticles.}

Caroline Thévenot, Abdel Khoukh, Stéphanie Reynaud, Jacques Desbrières, Bruno Grassl * Laboratoire de Physico-Chimie des Polymères (L.P.C.P.), UMR CNRS/UPPA 5067, IPREM FR 2606

Helioparc, 2 Avenue du Président Angot, 64053 Pau cedex 9, France

* Corresponding author (bruno.grassl@univ-pau.fr) 
ABSTRACT: Snake-cage gels were prepared using monodisperse polystyrene (PS) nano-size particles $(\mathrm{R}=200 \mathrm{~nm})$ in place of the more usually used linear polymer. The kinetics of the formation of the complementary polyacrylamide (PAM) hydrogel was studied alone or in the presence of the PS nanoparticles by ${ }^{1} \mathrm{H}-\mathrm{NMR}$. Without PS, the reactivity ratios of the acrylamide (Am) and the crosslinking agent $N, N^{\prime}$-methylene-bisacrylamide (BisAm) were computed using the initial kinetics of PAM gel at high crosslinker concentration $\left(\mathrm{r}_{\mathrm{A}}=0.52, \mathrm{r}_{\mathrm{B}}\right.$ $=5.2$, for Am and BisAm respectively). In the presence of PS, during the formation of nanoparticles composite gels (NPC gels), there was a decrease of the conversion rate with an increasing fraction of PS nanoparticles. This could be explained by steric effects which induce an increase of the elastic modulus of the matrix with the increasing fraction of PS nanoparticles. There was a considerable increase of the rheological properties of the NPC gels (i.e. tensile modulus) which was more pronounced at higher fractions of nanoparticles. We used the particular mechanical properties to develop a stimulus responsive ("smart”) material, i.e. a mechanoelectrical effect which may be used in the development of soft and wet tactile sensing devices

Keywords: nanoparticles, hydrogel, kinetics, rheological properties, NMR spectroscopy. 


\section{Introduction}

Hydrogels are materials that swell and hold high amounts of water without losing their shape. ${ }^{1}$ Polymers and copolymers of acrylamide (Am) are the most commonly used hydrogels and they have been widely studied. Polyacrylamide (PAM) hydrogels have found applications in water purification and irrigation, ${ }^{2}$ in improving soil texture, in pesticide formulations to limit spray drift ${ }^{3}$ and in medical applications. ${ }^{4}$ They are also used in molecular biology laboratories as matrices for separating nucleic acid components during DNA sequence analysis and protein identification. ${ }^{5}$ PAM hydrogels can absorb relatively high amounts of water furthermore, their swelling capacity is not very sensitive to $\mathrm{pH}$ or electrolytes. ${ }^{6}$ For some applications, high water absorption capacity is desired because it increases the permeability and the biocompatibility of the hydrogels. However, these hydrogels present poor mechanical properties because water does not contribute to mechanical strength. ${ }^{7}$ To increase the range of applications, two types of approaches are necessary: (i) controlling the microstructure restricting inhomogeneities and (ii) improving the mechanical strength of these materials while maintaining their water absorption capacity.

To produce hydrogels with relatively high mechanical strength combined with high water content, some procedures have been reported: (i) “topological (TP) gel”. ${ }^{8}$ The TP gels have figure-of-eight crosslinkers that can slide along the polymer chains. Reflecting this flexible crosslinker, TP gels absorb large amounts of water, and can be highly stretched without fracture. (ii) "nanocomposite (NC) gel”. ${ }^{9}$ In NC gels, polymer chains can be crosslinked by inorganic clay slabs on the scale of a several tens of nanometers, instead of organic crosslinking agents. ${ }^{10,11}$ The NC gels are also highly stretchable, and possess other favorable physical properties such as excellent optical transparency (iii) “interpenetrating polymer network (IPN)”. ${ }^{12,13}$ IPN gels consist of two interpenetrating polymer networks: one is made of highly crosslinked rigid polymers and the other is made of loosely crosslinked flexible 
polymers. (iv) "snake-cage (SC) gel”. In SC gels a linear hydrophobic polymer ${ }^{14}$ or polyelectrolyte ${ }^{15}$ (snake) with good mechanical properties is entrapped in crosslinked hydrophilic polymer (cage).

These types of gels with high mechanical strengths have made a breakthrough in finding wide applications in industrial and biomedical fields, and also raise fundamental problems in gel science. In our case, we studied particular gels, i.e. PAM hydrogels containing slightly crosslinked polystyrene (PS) nanoparticules called nanoparticles composite gels (NPC gels), which belong to the family of snake-cage (SC) gels where monodisperse, hydrophobic and non-ionic nanoparticles of PS take the place of the linear polymer. We used the particular mechanical properties to develop a stimulus responsive (“smart”) material, i.e. a mechanoelectrical effect which may be used in the development of soft and wet tactile sensing devices

In this work, we studied the polymerization kinetics of these NPC gels by ${ }^{1} \mathrm{H}-\mathrm{NMR}$ spectroscopy and rheological properties. The hydrophobic particles were prepared by direct (o/w) emulsion polymerization. The free radical polymerization process and the mechanical properties of these new type of snake-cage gel were compared with those of conventional hydrogels (i.e., without particles) with similar PAM content and degree of crosslinks (PAM gels). The difference in their elastic properties was used for producing an electrical potential by simple compression between two hydrolyzed NPC gels. 


\section{Experimental section}

Materials. For nanoparticles synthesis, styrene (Aldrich) was purified by passing through a basic activated alumina column before use. Ammonium persulfate [APS, $\left(\mathrm{NH}_{4}\right)_{2} \mathrm{~S}_{2} \mathrm{O}_{8}$ ] and divinylbenzene were purchased from Aldrich and used as received. Two surfactants were used for the preparation of nanoparticles: Igepal CO $897^{\odot}$ (called NP40, hydrophilic-lypophilic balance HLB=17.8) obtained from Rhodia $^{\odot}$ and $\mathrm{Ninol}^{\odot}(\mathrm{HLB}=11.4)$ obtained from Stepan ${ }^{\odot}$. Surfactants were used as received. For NPC gels synthesis, acrylamide (Am) (purity >99 \%) and $N, N^{\prime}$-methylene-bisacrylamide (BisAm) (purity $>99 \%$ ) were respectively purchased from Aldrich and Fluka. 2, 2'-Azobis (2-methylpropionamide)dihydrochloride called VAZO ${ }^{\circledR 56 W S P}$ from Dupont Chemicals $\left(M_{\mathrm{w}}=271.19 \mathrm{~g} \cdot \mathrm{mol}^{-1}, t_{1 / 2}=10 \mathrm{~h}\right.$ at $\left.56{ }^{\circ} \mathrm{C}\right)$ was used as initiator for hydrogel polymerization. Water was distilled three times on Pyrex-quartz glass apparatus and prefiltered with $0.22 \mu \mathrm{m}$ Millipore filter just before use to exhibit conductivity below $0.055 \mu \Omega . \mathrm{cm}^{-1}$. Reaction mixtures were prepared with the filtered water. All ${ }^{1} \mathrm{H}-\mathrm{NMR}$ spectra were recorded with $\mathrm{D}_{2} \mathrm{O}$ as solvent (purchased from SDS, purity $>99.9 \%$ ).

Crosslinked polystyrene latex particles. Latex particles were synthesized according to the procedure used by Kohut-Svelko et al. ${ }^{16}$ The reaction vessel was purged with nitrogen to remove traces of oxygen. In a typical polymerization, reaction mixture of non ionic surfactants (NP40 62wt\%, Ninol 38wt \%) was dissolved in distilled water (200 mL) in a three-necked round-bottom flask under a nitrogen atmosphere. The purified monomers styrene (87 g, $0.836 \mathrm{~mol}$ ) and divinylbenzene (3.7 wt \% vs. styrene) used as the crosslinking agent, were added to the aqueous solution and emulsified under vigorous stirring. This emulsion was then heated under mechanical stirring up to $70{ }^{\circ} \mathrm{C}$. The aqueous solution of APS ( $0.3 \mathrm{~g}$ in $5 \mathrm{~mL}$ of water) was then added drop by drop. The polymerization was then allowed to proceed for $24 \mathrm{~h}$ at $70{ }^{\circ} \mathrm{C}$ under mechanical stirring. 
Nanoparticles analyses. Nanoparticles were characterized on a dynamic light scattering apparatus DL 135-45, developed by the IFP (French Petroleum Institute). The technique works on a very thin suspension layer to avoid multiscattering phenomena and can be successfully applied to concentrated, dense, and opaque solutions (laser wavelength : 633 $\mathrm{nm}$ ).The results were confirmed by classical DLS (Sematech) on very diluted latex solutions (solvent, water; wavelength, $514.5 \mathrm{~nm}$ ). To avoid particles aggregation, solutions were put into ultrasonic bath during one hour.. Moreover, Environmental Scanning Electron Microscope (ESEM) analysis (Figure 1), carried out using an ElectroScan instrument operating at $20 \mathrm{kV}$, showed that particles are monodisperse. Radius obtained was (200 \pm 30$) \mathrm{nm}$ from both techniques

\section{Insert Figure 1}

Gel samples. Gels were prepared by classical radical polymerization with BisAm as crosslinker and VAZO56 as initiator at a temperature reaction of $56{ }^{\circ} \mathrm{C}$, unless otherwise stated. Reaction mixtures were prepared few hours before polymerization and thoroughly mixed for $2 \mathrm{~h}$ prior to use. The sample solutions were degassed with nitrogen. Hydrogels were prepared by adding monomer (Am), crosslinker (BisAm), initiator (VAZOß56WSP), in $\mathrm{D}_{2} 0$ and water for NMR and rheological experiments, respectively. The nanoparticles composite hydrogels (NPC gels) containing hydrophobic nanoparticles were prepared by addition of PS latex into the above solution. To prepare different compositions for NPC gels, amounts of monomer, crosslinker, initiator and PS latex have been varied over a wide range in order to emphasize their own effect in the polymerization process.

Gels compositions. In this paper, several terms are introduced to classify the hydrogels compositions: \%M refer the total concentration of monomers as a weight percentage; \%B, \%I refer respectively to the weight concentrations of crosslinking agent, initiator taking into 
account both acrylamide and crosslinker; $\phi$ represents the volume fraction of polystyrene particles to the total volume of the reaction mixture, $[\mathrm{A}]$ and $[\mathrm{B}]$ are the molar concentrations of vinylic units of acrylamide and BisAm respectively and $\left[I_{2}\right]_{0}$ is the initial molar concentration of initiator, taking into account the volume of the aqueous phase without the contribution of hydrophobic PS nanoparticles.

$$
\begin{aligned}
& \% M=\frac{\text { total mass of monomers }(g)}{\text { total mass of reaction mixture }(g)} \times 100 \\
& \% B=\frac{\text { mass of crosslinking agent }(g)}{\text { total mass of monomers }(g)} \times 100 \\
& \% I=\frac{\text { mass of initiator }(g)}{\text { total mass of monomers }(g)} \times 100
\end{aligned}
$$

${ }^{1} \mathbf{H}-N M R$ monitoring. NMR apparatus is a $400 \mathrm{MHz}$ Bruker Advanced AM400 spectrometer. Once the reaction mixtures prepared and mixed, there were poured into NMR glass tubes (5 mm interior diameter), purged with nitrogen and sealed with paraffin film. Around 50 measurements were taken continuously during the polymerization in order to follow the monomers units conversion as a function of time (see Figure 2). Indeed, we considered three integrations: the first one corresponds to vinylic protons of monomers (at 6.0-6.7 ppm), the second one corresponds to methylene protons of BisAm (4.95 ppm) and the third one to protons of aliphatic carbon in the polymer backbone to network gathered (at 1.7$2.7 \mathrm{ppm})$. Thus, we obtained the overall monomers conversion against time.

\section{Insert Figure 2}

Rheological measurements. Rheological measurements of the NPC gels were carried out using a Bolhin CVOR 150 rheometer equipped with a Peltier device for temperature control. Parallel-plate geometry was used with a gap of $2 \mathrm{~mm}$. The upper plate was made of stainless 
with a $40 \mathrm{~mm}$ diameter and the lower plate was a stainless Peltier surface. We noticed a strong adhesion of NPC gel in the stainless surface. Reaction mixture was prepared and mixed as described above and placed into the parallel plates at a temperature of $56{ }^{\circ} \mathrm{C}$ in order to form the hydrogel in situ. Once the polymerization was complete, dynamic frequency sweep tests were recorded in an auto-stress mode (equivalent to constant strain mode) at deformation $\gamma^{\ell}=0.10$ maintained constant over the a frequency range of $0.1-10 \mathrm{~Hz}$ at $25{ }^{\circ} \mathrm{C}$. For all experiments, linear regime was checked and a solvent trap containing silicon oil was used to minimize evaporation. A thin film of oil was applied around the samples (once the gel state reached) when it was necessary. We compensated for the density and thermal expansions of the experimental set up by using normal force compensation.

Kinetics aspect of the copolymerization. For propagation in free radical copolymerization, it is generally considered that the reaction rate for a given comonomer depends only on which monomer bears the radical at the chain terminus ${ }^{17}$. For the molar concentrations of vinylic units in Am (A) and in BisAm (B) and by considering the equal reactivity of propagating species whatever the polymerization degree of propagated chains is, this leads to propagation equations of the form:

$-\frac{d[A]}{d t}=k_{A A}[A]\left[A^{*}\right]+k_{B A}[A]\left[B^{*}\right] \quad$ (5) $-\frac{d[B]}{d t}=k_{B B}[B]\left[B^{*}\right]+k_{A B}[B]\left[A^{*}\right] \mathbf{( 6 )}$

where $\mathrm{A}^{*}$ and $\mathrm{B}^{*}$ are the propagating radicals of $\mathrm{A}$ and $\mathrm{B}$, respectively; $k_{\mathrm{AA}}$ and $k_{\mathrm{BB}}$ the rate constants of homopropagation reactions, $k_{\mathrm{AB}}$ and $k_{\mathrm{BA}}$ the rate constants of cross-propagation reactions. The equations rate for propagating radicals $\mathrm{A}^{*}$ and $\mathrm{B}^{*}$, are: 


$$
\begin{aligned}
& \frac{d\left[A^{*}\right]}{d t}=2 F k_{d}\left[I_{2}\right]-k_{A B}[B]\left[A^{*}\right]+k_{B A}[A]\left[B^{*}\right]-k t_{A A}\left[A^{*}\right]^{2}-k t_{A B}\left[A^{*}\right]\left[B^{*}\right] \\
& \frac{d\left[B^{*}\right]}{d t}=2 F k_{d}\left[I_{2}\right]-k_{B A}[A]\left[B^{*}\right]+k_{A B}[B]\left[A^{*}\right]-k t_{B B}\left[B^{*}\right]^{2}-k t_{A B}\left[A^{*}\right]\left[B^{*}\right]
\end{aligned}
$$

where $2 F k_{\mathrm{d}}\left[\mathrm{I}_{2}\right]$ means the formation rate of active centers $\mathrm{I}^{*}$ issued from the chemical decomposition of the initiator $\mathrm{I}_{2}, \mathrm{~F}$ the efficiency parameter of initiator, $k_{\mathrm{tAA}}\left[\mathrm{A}^{*}\right]^{2}$ and $k_{\mathrm{tBB}}\left[\mathrm{B}^{*}\right]^{2}$ the rates of homotermination reactions and $k_{\mathrm{tAB}}\left[\mathrm{A}^{*}\right]\left[\mathrm{B}^{*}\right]$ the rate of crosstermination reactions. The quasi steady-state approximation applied to radicals assumes that the variation of $\left[\mathrm{A}^{*}\right]$ and $\left[\mathrm{B}^{*}\right]$ is negligible towards the other reaction rates, thus $\mathrm{d}\left[\mathrm{A}^{*}\right] / \mathrm{d} t=$ $\mathrm{d}\left[\mathrm{B}^{*}\right] / \mathrm{d} t=0$. In terms of the creation and loss of propagating radicals, the contribution of initiation and termination reactions is negligible compared to that of the cross-propagations, thus:

$$
\begin{aligned}
& 2 F k_{d}\left[I_{2}\right]=k t_{A A}\left[A^{*}\right]^{2}-k t_{A B}\left[A^{*}\right]\left[B^{*}\right]=k t_{B B}\left[B^{*}\right]^{2}-k t_{A B}\left[A^{*}\right]\left[B^{*}\right] \\
& \frac{\left[A^{*}\right]}{\left[B^{*}\right]}=\frac{k_{B A}}{k_{A B}} \frac{[A]}{[B]}=\left(\frac{k_{t A A}}{k_{t B B}}\right)^{0.5}
\end{aligned}
$$

The instantaneous composition of copolymer was determined using the Mayo-Lewis ${ }^{18}$ copolymer equation given below:

$$
\frac{d[A]}{d[B]}=\left(\frac{[A]}{[B]}\right)\left(\frac{r_{A}[A]+[B]}{[A]+r_{B}[B]}\right)
$$

where the reactivity ratios $r_{\mathrm{A}}$ and $r_{\mathrm{B}}$ are defined as following:

$$
r_{A}=\frac{k_{A A}}{k_{A B}} \quad ; \quad r_{B}=\frac{k_{B B}}{k_{B A}}
$$

The instantaneous mol fraction of $[\mathrm{A}]$ incorporated, $F_{\mathrm{A}}$, is given by: 


$$
F_{A}=\frac{d[A]}{d[A+B]}=\frac{r_{A} f_{A}^{2}+f_{A}\left(1-f_{A}\right)}{r_{A} f_{A}^{2}+2 f_{A}\left(1-f_{A}\right)+r_{B}\left(1-f_{A}\right)^{2}}
$$

where $f_{\mathrm{A}}$ and $f_{\mathrm{B}}$ are the mol fractions of monomers $\mathrm{A}$ and $\mathrm{B}$, respectively. $F_{\mathrm{B}}$ is obtained by interchanging the subscripts $\mathrm{A}$ and $\mathrm{B}$. These expressions form the basis for finding composition and sequence length distributions.

$$
f_{A}=\frac{[A]}{[A]+[B]} \quad ; \quad f_{B}=\frac{[B]}{[A]+[B]}
$$

If the composition drift and initiator decomposition rate are slow, the concentrations of $\mathrm{A}^{*}$ and $\mathrm{B}^{*}$ can be assumed almost constant throughout the reaction, so that $[\mathrm{A}]$ and $[\mathrm{B}]$, at least at early values of conversion, will yield first-order decay kinetics of the form:

$$
[A]=[A]_{0} e^{-\alpha_{A} t} \quad ; \quad[B]=[B]_{0} e^{-\alpha_{B} t}
$$

where $\alpha_{\mathrm{A}}$ and $\alpha_{\mathrm{B}}$ are the apparent rate constants of propagation reactions of $\mathrm{A}$ and $\mathrm{B}$ respectively, with

$$
\alpha_{A}=k_{A A}\left[A^{*}\right]+k_{B A}\left[B^{*}\right] ; \quad \alpha_{B}=k_{B B}\left[B^{*}\right]+k_{A B}\left[A^{*}\right]
$$

Otherwise, the reactivity ratios can be determined by finding the ratio of these rate constants, determined over early conversion, for separate experiments in which the relative initial concentrations $[\mathrm{A}]_{0}$ and $[\mathrm{B}]_{0}$ varied. Using equations 9,10 and 12 that yields

$$
\frac{\alpha_{A}}{\alpha_{B}}=\frac{1+r_{A} \frac{[A]_{0}}{[B]_{0}}}{\frac{[A]_{0}}{[B]_{0}}+r_{B}}
$$




\section{Results and Discussion}

\section{Kinetics aspect by ${ }^{1} \mathrm{H}$ NMR}

\subsection{PAM gels at low crosslinker concentration}

\section{Insert Table 1}

Figure 2 shows raw spectra for a typical ${ }^{1} \mathrm{H}-\mathrm{NMR}$ monitoring experiment (run A3 in Table 1). The signal at $4.7 \mathrm{ppm}$ corresponds of the residual water in $\mathrm{D}_{2} 0$. The signal decrease between 6.0 and $6.7 \mathrm{ppm}$ and the signal increase between 1.7 and 2.7 ppm show the conversion of vinylic units $\mathrm{A}$ and $\mathrm{B}$, whereas the signal decrease at $4.95 \mathrm{ppm}$ is due chiefly to the conversion of the crosslinking agent, i.e. it corresponds to one vinylic function of BisAm.

These three signals yield the monomers conversion, according to the following equations:

$p_{\mathrm{A}}=1-[\mathrm{A}] /[\mathrm{A}]_{0}$

$p_{\mathrm{B}}=1-[\mathrm{B}] /[\mathrm{B}]_{0}$

The first series of experiments (series A in Table 1), were prepared with different amounts of initiator while the fraction of crosslinking agent \%B was kept roughly constant. Unfortunately, the concentration of $B$ was too small to make the signal at $4.95 \mathrm{ppm}$ accurate. Figure 3 shows only monomer conversion $p_{\mathrm{A}}$ versus time for different initiator concentrations while keeping \%B and \%M constant.

\section{Insert Figure 3}

The curves in Figure 3 can be treated approximately as first order over a significant portion of the reaction. Nevertheless, fits of the form:

$p_{A}=1-\exp \left(-\alpha_{\mathrm{A}} \cdot t\right)$ 
are also shown in Figure 3, where $\alpha_{\mathrm{A}}$ is the first-order decay rate constant defined by equation 15. The fit is best for all the reactions presented in Table 1 . The $\ln [\mathrm{A}]$ versus time curves did not show a steepening with increasing conversion. This indicates that auto acceleration was absent or insignificant. The inset in Figure 3 shows $\alpha_{\mathrm{A}} \mathrm{vs}\left[\mathrm{I}_{2}\right]_{0}{ }^{0.5}$ corresponding to equation 17 with $\left[\mathrm{B}^{*}\right]<<\left[\mathrm{A}^{*}\right]$ and plotted for runs A1 to A4. The linearity is quite good for all values. The slope of the plot is hence related to the apparent rate constants $k_{\text {app }}$ via

$\mathrm{d} \alpha_{\mathrm{A}} / \mathrm{d}\left[\mathrm{I}_{2}\right]_{0}^{0.5}=k_{\text {app }}=1.09 \times 10^{-1} \mathrm{~s}^{-1} \cdot \mathrm{mol}^{-1 / 2} \cdot \mathrm{L}^{1 / 2}$

for $\% \mathrm{~B}=1$ and where the approximation is made that the initiator decay rate is slow compared to the time for the complete reaction, so that $\left[\mathrm{I}_{2}\right] \approx\left[\mathrm{I}_{2}\right]_{0}$. As expected, the reaction time is short compared to the half-time life of initiator $\left(10 \mathrm{~h}\right.$ at $\left.56^{\circ} \mathrm{C}\right)$. Our system using azoic initiator is significantly faster than the classical one using a persulfate initiator for the free radical homopolymerization of Am: $k_{\text {app }}=1.05 \times 10^{-2} \mathrm{~s}^{-1} \cdot \mathrm{mol}^{-1 / 2} \cdot \mathrm{L}^{1 / 2}$ and $4.58 \times 10^{-3} \mathrm{~s}^{-1} \cdot \mathrm{mol}^{-}$ ${ }^{1 / 2} \cdot \mathrm{L}^{1 / 2}$ at 50 and $60{ }^{\circ} \mathrm{C}$ respectively. ${ }^{19}$ These values favor the formation of the NPC gel in reasonable time with $\% \mathrm{~B}=1$, a small amount of initiator and a conversion close to $100 \%$.

The series of experiments concerning the same reaction mixture at different temperatures (cf. Table 1, Runs B1 to B4) is plotted on the Figure 4. The inset shows a linear variation of $\ln \left(\alpha_{\mathrm{A}}\right)$ versus $1 / T$ ( $\mathrm{T}$ in Kelvin) according to the Arrhenius relation

$\alpha_{\mathrm{A}}=\alpha_{\mathrm{A}}^{0} \cdot \exp (-\Delta E / R T)$

where $\Delta E$ is the apparent activation energy of the global process in this free radical copolymerization of acrylamide and $R$ the perfect gas constant. The data from the inset Figure 4 yield activation energy $\Delta E=67 \mathrm{~kJ} \mathrm{~mol}^{-1}$ as the same order of classical radical polymerization. ${ }^{19}$ 


\subsection{PAM gels at high crosslinker concentration}

A series was prepared with high concentrations of crosslinker (runs C5 to C11 with \%B varying from 5 to 27) to determine the influence of a great increase of the amount of vinylic unit. Indeed, if [B] is high enough, the signal at $4.95 \mathrm{ppm}$ is accurate. So, kinetics study can be performed with both considering the conversion of the two monomers ( $p_{\mathrm{A}}$ and $\left.p_{\mathrm{B}}\right)$ and determining $\alpha_{\mathrm{A}}$ and $\alpha_{\mathrm{B}}$.

Figure 5 shows the initial decay rates, i.e. the initial slope of semi-logarithmic plot of monomer concentration $\left(\left(1-p_{\mathrm{A}}\right)\right.$ and $\left.\left(1-p_{\mathrm{B}}\right)\right)$ versus time for runs $\mathrm{C} 7$ and $\mathrm{C} 11$. The monomer decay in each case follows a first-order kinetics over almost the entire range of the experiments, as shown in Figure 6. Steady state approximations and slow monomer concentration ratios variation fit well. Inset of Figure 6 shows the determination of $r_{\mathrm{A}}$ and $r_{\mathrm{B}}$ using the ratio of A and B rate constants from equation 18 (runs C5 to C9). The experimental values of $r_{\mathrm{A}}$ and $r_{\mathrm{B}}$ are $0.52 \pm 0.04$ and $5.2 \pm 0.8$, respectively. Even in the case of high drift, the initial decay rates should still yield a good approximation for the reactivity ratios. This method, using rate constants, issued from NMR data is convenient and accurate provided that the same initiator concentration is used in each experiment.

Nevertheless, from equation (18), it can be seen that the value of $r_{B}$ is dependent on low value of the ratio $[\mathrm{A}]_{0} /[\mathrm{B}]_{0}$ where there is little variation in $\alpha_{\mathrm{A}} / \alpha_{\mathrm{B}}$. The main conclusion is the very high reactivity of BisAm compared with Am, as already reported elsewhere $\left(r_{\mathrm{A}}=0.57\right.$ and $r_{\mathrm{B}}=3.4$ at $22{ }^{\circ} \mathrm{C}{ }^{20}$ ). As we can observe in Figure 6, in the first 1000s of the copolymerization, the major part of BisAm was consumed while the Am monomer conversion reached only 0.86 . This phenomenon was enhanced by increasing $[\mathrm{B}]_{0}$.

\section{Insert figure 5 and 6}


Moreover, the use of the Mayo-Lewis theory allows computing the sequence length distribution. $W_{\mathrm{BB}}$ denotes the probability that $\mathrm{B}^{*}$ adds to $\mathrm{B}$. Using the reactivity ratios, this can be expressed, at any conversion point $p$, during the reaction as

$$
W_{B B}(p)=\frac{r_{B} f_{B}(p)}{f_{B}(p)\left(r_{B}-1\right)+1}
$$

Where conversion point $p$ is the total conversion of monomers.

The probability of having a sequence of $k$ monomers B in a row , followed by a monomer $\mathrm{A}$, $P_{\mathrm{B}, k}$, then follows the well-known geometric distribution : ${ }^{17}$

$$
p_{B, k}=\left(1-W_{B B)}\right) W_{B B}^{k-1}
$$

$p_{\mathrm{B}, k}(p)$ from measurements at each point $p$ is hence the instantaneous sequence length distribution. The moments of this distribution are well-known. The instantaneous numberaverage sequence length of monomer $\mathrm{B},\left\langle N_{\mathrm{B}}\right\rangle_{\mathrm{n}}$, at conversion point $p$, is

$$
\left\langle N_{B}\right\rangle_{n}(p)=\frac{1}{1-W_{B B}(p)}
$$

To obtain the appropriate expressions for monomer A, the subscript A is substituted for B in each variable in the above equations.

Figure 7 shows the probability that $\mathrm{B}^{*}$ adds to $\mathrm{B}$ and the instantaneous number $\mathrm{B}$ sequence lengths, $<N_{\mathrm{B}}>_{\mathrm{n}}$ vs. conversion, for experiment C6. These values were computed from eqs. 2325, using the value of $r_{\mathrm{B}}=5.2$.

\section{Insert figure 7}

Figure 8 shows a mechanism of the network formation, by taking into account the very strong difference between $r_{\mathrm{A}}$ and $r_{\mathrm{B}}\left(r_{\mathrm{A}}=0.52 \pm 0.04\right.$ and $r_{\mathrm{B}}=5.2 \pm 0.8$ in our system). Run C6 was chosen in order to demonstrate the occurring phenomena. Before polymerization begins, there is a small part of crosslinker molecules in the reaction mixture with high concentration of 
vinyl groups. Then, free radical polymerization begins with a few chains of linear PAM growing incorporating some BisAm molecules. Indeed, with $[\mathrm{B}]=55.10^{-3} \mathrm{~mol}^{-1} \cdot \mathrm{L}^{-1}$, an average quantity of one BisAm molecule against 9 Am molecules are polymerized $\left(\mathrm{F}_{\mathrm{B}}=\right.$ 0.11). Moreover, the determination of $\left\langle N_{\mathrm{B}}\right\rangle_{\mathrm{n}}$ (at $\mathrm{p}=0,\left\langle N_{\mathrm{B}}\right\rangle_{\mathrm{n}}=1.3$ ) can be understood as an average of the incorporation in the PAM growing chain of a sequence of two BisAms at one point followed further by two individual BisAms $(4 / 3 \approx 1.3)$. In consequence (Figure $8 a)$, the sequence of two BisAms would be the cause of the initial formation of very dense and crosslinked microdomains. However, the incorporation of only one BisAm permits the formation of simple node. Finally (Figure 8b), these phenomena, occurring during the early stages of the polymerization, lead to a network which already exhibits structural inhomogeneities.

\section{Insert figure 8}

Other factors than the reactivity ratios have been studied to explain these inhomogeneities such as the nature of the crosslinker, ${ }^{21}$ the nature of the solvent ${ }^{22}$ and the temperature. ${ }^{23}$ Finally, our results confirm the commonly held view of the existence of microdomains of highly crosslinked and reticulated clusters, joined by PAM chains. ${ }^{22,24,25}$

Thus, using NMR technique for studying polymer networks is very interesting because a mechanism of the network formation can be built thanks to the determination of some kinetics constants; in consequence, the microstructure of PAM gels can be controlled by restricting inhomogeneities. Indeed, small amount of $\mathrm{B}$ with \%M = 7 permits limiting high crosslinked microdomains and inhomogeneities. That is why these concentrations (or less) will be used for the following kinetics study of NPC gels. After the kinetics study of PAM gels, the formation of NPC gels and their mechanical strength were studied in the aim of widest future applications. 


\subsection{Nanoparticle composite gel (NPC)}

In this part, the influence of the introduction of latex PS nanoparticles in the reaction mixture was analyzed in terms of apparent rate constants of propagation reactions of A with a low concentration of B (Table 2).

\section{Insert Table 2 - Insert Figure 9}

For experiments D1 to D5, the incorporation of latex particles showed a decrease of $\alpha_{a}$ along with an increase of the nanoparticles volume fraction, $\phi$. Although $\alpha_{a}$ is lower, the final conversion of $\mathrm{P}_{\mathrm{A}}$ for $\mathrm{D} 5$ and $\mathrm{D} 6$ experiments can reach up to 0.8 but the polymerization rate is slower and the time to have the same conversion is higher than for the PAM matrix alone (about 4000s). This result was unexpected: indeed, the nanoparticles which are just incorporated in the PAM matrix are neutral in terms of reactivity and were not supposed to influence the kinetics of the crosslinked PAM. This feature occurred without any modification of the first-order kinetic plot, as shown in Figure 9. As shown in the following section, the incorporation of latex particles increased the elastic modulus of the gel, and could explain the slower propagation rate. However, comparison of runs D5 and D6 performed with and without crosslinker exhibited the same rate constants (values of $\alpha_{A}$ for D5 and D6 are respectively equal to $0.37 \times 10^{-3}$ and $0.38 \times 10^{-3} \mathrm{~mol} . \mathrm{s}^{-1} \cdot \mathrm{L}^{-1}$ ) proves that gel effect does not occur in our system. Moreover, the presence of surfactants in the reaction medium could act as an inhibitor by chain transfer, since propagating radicals will be removed and very few new ones will be created. In this case, chain transfer agent actually seemed to lead to a decrease of the conversion rate. This was explained by runs D7 and D8, with no PS particles and different overall concentration of surfactants mixture used for PS nanoparticles (D7: Ninol $=0.48 \mathrm{wt} \%$ and NP40 $=1.18 \mathrm{wt} \%$, and D8: Ninol $=0.26 \mathrm{wt} \%$ and NP40 $=0.59 \mathrm{wt} \%)$. The results were compared to those obtained for the experiment D9 containing no surfactant and showed no or very few contribution of the surfactants in the kinetic process of PAM gel formation. 
The decrease in conversion rate along with the fraction of PS particles cannot be explained by gel effect or by the presence of residual surfactant. Instead, we think that this feature is rather due to a steric effect. Indeed, the latex particles are spherical objects; we can assume that they adopt a regular space organization of cubic lattice in the gel. Several types of cubic lattices could be considered, for example a simple cubic (sc), a body-centered cubic (bcc), or a facecentered cubic (fcc) structures. The lattice constant, $a_{i}$, is related to the distance between the planes, $d_{h k l}$, through the equations : $a_{\mathrm{sc}}=d_{100}, a_{\mathrm{bcc}}=2^{1 / 2} d_{100}$, and $a_{\mathrm{fcc}}=3^{1 / 2} d_{100}$. Considering that $a_{i}^{3}$ is the cubic lattice volume and that there are 1, 2, and 4 scattering objects per lattice for the sc, bcc, and fcc, respectively, it is then possible to write that the lattice constant $a_{\mathrm{i}}$ is a function of the radius $\mathrm{R}$ and of the particles volume fraction $\phi$ :

$$
a^{3}=\frac{\alpha\left(4 / 3 \pi R^{3}\right)}{\phi}
$$

Where $\alpha$ is the prefactor depending of the nature of the cubic lattices, 1,2 and 4 for sc, bcc, and fcc, respectively. In the case where $\mathrm{R}=202 \mathrm{~nm}$ and $\phi=0.13$, the edge to egde distance $d$ between surface particles are 239, 481 and $169 \mathrm{~nm}$ for simple cubic (sc), a body-centered cubic (bcc), or a face-centered cubic (fcc) structure respectively. Moreover, the radical polymerisation of Am with no crosslinker (at $56^{\circ} \mathrm{C}$ and with the same initiator concentration as in run A3) provided a linear PAM chains with high molecular weight $\left(M_{\mathrm{w}}=1.35 \times 10^{6}\right.$ g.mol ${ }^{-1}$ ) and a radius of gyration of $82 \mathrm{~nm}$. The corresponding diameters are of the same order of magnitude as the distance $d$ between surface particles. In this case, the particles could be considered as a hindrance of the growing chain and slow down the propagation rate of the growing chain in the reaction medium. In fact, the rate of propagation $\alpha_{\mathrm{A}}$ decreased by a factor close to ten between run D9 containing no particle and runs D5 and D6 realized with $13 \%$ of PS particles, with and without crosslinker, respectively. It is clear that if we take into 
account these geometric considerations, the decrease in conversion rate with the fraction of PS particle could surely be explained by a steric effect.

In addition, even if this spectroscopy technique is widely used for monitoring kinetics on linear polymers, our study shows that it is also easily possible in the specific case of three dimensional polymers containing additional particles or not. In our knowledge, this specific case was not yet developed in literature.

\section{Rheological behavior}

Thanks to the kinetics aspects described above, we ensured that NPC gels syntheses occur in classical ways and reach to completion. So, we wanted to study the rheological properties of these NPC gels. As previously shown, PS latex nanoparticles were considered as well-known model nanoparticles which can be easily used in our hydrogels systems. The influence of PS nanoparticles on rheological behavior of NPC gels was studied in the same experimental conditions as for kinetics study with a volume fraction of nanoparticles $\phi$ ranged from 0 to 26\%. The samples composition is given in Table 3 (runs G1 to G6).

\section{Insert Table 3}

Once the polymerization was achieved, dynamic oscillatory tests in frequency were performed between 0.1 and $10 \mathrm{~s}^{-1}$. The good reproducibility of the results of $G^{\prime}(w)$ confirmed that the polymerization has reached completion. For all hydrogels, $G^{\prime}(w)$ stayed constant with a standard deviation close to $0.5 \%$, and $G^{\prime \prime}(w)$ could be considered negligible against $G^{\prime}(w)$. The stability and the relative large value of $G^{\prime}(w)$ compared to $G^{\prime \prime}(w)$ over a range of at least three frequency decades is a classical characteristic feature of a crosslinked hydrogel. ${ }^{7,26}$ This stability also indicated that the permanent chemical crosslinks were not destroyed by the increasing frequency at constant strain $\gamma^{0}$. Moreover, $\gamma^{0}=0.10$ was within the linearity 
domain. Indeed, $G^{\prime}$ was measured as a function of increasing strain amplitude $\gamma^{0}$. $G^{\prime}$ remained constant for low strains $\left(\gamma^{0}<0.35\right)$. The linearity domain decreased as the elasticity of the hydrogel increased.

Experimental data are reported in Table 3 and Figure 10 shows the variation of G' with the volume fraction, $\phi$ of PS nanoparticles. The experimental results showed a strong reinforcement of rheological properties of NPC gels which was greater at higher nanoparticles content.

In order to evaluate in a better way our NPC gels, we used a rheological behaviour modelling of a composite of two elastic bodies without interfacial tension, proposed by Kerner ${ }^{27}$ and revisited by Bousmina ${ }^{28}$. The elastic modulus of the blend $G_{\mathrm{b}}$ can be related to the elastic modulus of the matrix $G_{\mathrm{m}}$ and the dispersed phase $G_{\mathrm{d}}$ as follows:

$$
G_{b}=G_{m}\left(\frac{\left(2 G_{d}+3 G_{m}\right)+3 \phi\left(G_{d}-G_{m}\right)}{\left(2 G_{d}+3 G_{m}\right)-2 \phi\left(G_{d}-G_{m}\right)}\right)
$$

We can consider that $G_{\mathrm{d}}$ is close to $6.10^{9} \mathrm{~Pa}^{29}$ and the elastic modulus of the matrix $G_{\mathrm{m}}=$ 2150 Pa as measured for the hydrogel without PS nanoparticles (run G1). Thus, a theoretical behavior was plotted and reported in Figure 10 along with our experimental data. It is obvious that our NPC gel systems do not follow the Kerner model i.e. that elastic modulus of the blend $G_{b}$ obtained are higher than the expected ones for volume fractions higher than 0.05 . This difference could be explained with the elastic modulus $G_{\mathrm{m}}$ values. Indeed, when nanoparticles are incorporated into the gel, the kinetics of NPC gels is greatly dependent on the nanoparticles content (see kinetics section) and the rheological properties may be affected by the modifications of the gelation process. Such, $G_{\mathrm{m}}$ drastically increased as the volume fraction of nanoparticles contained in our NPC gels. Thus, $G_{\mathrm{m}}$ obtained from eq. 27 shows 
this phenomenon: 7476 and 19219 Pa for G4 and G6 respectively. Otherwise, a slight adhesive interaction between PS nanoparticles and PAM matrix can explain the difference between experimental and theoretical data.

\section{Insert Figure 10}

\section{Mechanoelectrical effects of hydrolysed NPC gels}

Hydrogels with high mechanical strength may have several applications and among them, we chose to evaluate the chemoelectrical properties of our systems.

It is well known that polyelectrolyte gels can contract or deform under an electrical stimulus, that is, a gel can convert the electrical energy into mechanical work. The reverse process was also previously reported, ${ }^{30}$ it produces electrical potential from mechanical deformation. As shown in Figure 11a, a cell containing two stacked layers of hydrolysed NPC was made: the bottom layer was a gel containing $26 \%$ of nanoparticles and the top one did not contain any particles. Indeed, the bottom part which presents interesting rheological properties shows also a different behaviour under compression (the deformation of this bottom layer is lower than the one of the top layerif the same stress is applied). A pair of platinum wire electrodes, one as reference and the other one as working electrode, was inserted to measure the electrical potential. When the top gel layer was compressed (with a $\Delta L_{1} / L$ deformation), the extra protons migrated to the bottom gel layer, slightly deformed $\left(\Delta L_{2} / L\right)$, through the interface until the Donnan equilibrium was reached. An electrical potential variation was observed during this period as shown in Figure 11b. These preliminary results showed that the tactile sensing systems were successfully made from polymer gel. Moreover, the electrical signal enhanced in proportion to the amplitude of the applied strain $\Delta L / L$ (or stress). 
On the basis of this principle, a soft and wet tactile sensing device could be developed by connecting the electrodes to two NPC gel layers exhibiting different elastic modulus, as previously shown.

\section{Insert Figure 11}

On the basis of swelling and contraction of a weak polyelectrolyte gel, Katchalsky et al. ${ }^{31}$ proposed a so-called "muscle” model which was referred to a chemomechanical system. Thanks to this similarity and the common feature with the natural tissue (softness, wetness, elasticity, and some other rheological specified characteristics), the soft mechanoelectrical system obtained from a NPC gel may open new possibilities in the investigation of artificial tissue-like tactile perception for robotics or psycho sensorial material area.

\section{Conclusion}

We studied particular gels which belong to the family of snake-cage gels where monodisperse, hydrophobic and non ionic nanoparticles take the place of the linear polymer. The polymerization kinetics of PAM hydrogel with and without polystyrene nanoparticles (NPC gels) has been performed by ${ }^{1} \mathrm{H}-\mathrm{NMR}$ spectroscopy. Reactivity ratios were computed using initial kinetics in the case of PAM gels at high crosslinker concentration. Furthermore, it is possible to determine the instantaneous and cumulative sequence length distribution and average, based on the Mayo-Lewis model. The different results and their interpretation are in accordance with previous studies on inhomogeneities in this kind of hydrogel.

For the NPC gels, the decrease of conversion rate with the PS nanoparticles content could be explained by a steric effect which probably induces an increase of the elastic modulus of the matrix and is related to nanoparticles content. The results show a strong reinforcement of mechanical properties of NPC gels which is more pronounced for the higher fraction of nanoparticles. These differences of rheological properties have been used for producing an 
electrical potential by simple compression between two hydrolyzed NPC gel layers. This concept can be used to develop a soft and wet tactile sensitive device. The soft mechanoelectrical system made with a NPC gel may open new possibilities in the investigation of artificial tissue-like tactile perception for robotics or psycho sensorial material area, for example.

\section{Acknowledgment}

The authors wish to thank Nicolas Kohut-Svelko for his help in the preparation of PS latexes,

Gérald Clisson and Francis Ehrenfeld for technical assistance. The Communauté d’Agglomération de Pau (France) is greatly thanked for financial support. The authors would like to acknowledge Virginie Pellerin for ESEM images, Roger C. Hiorns for help in the preparation of the manuscript and Jeanne François for initiating this work. 


\section{References}

(1) Osada, Y. ; Gong, J. P. ; Tanaka, Y., Journal of Macromolecular Science-Polymer Reviews, 2004, C44, 87-112.

(2) Entry, J. A. ; Sojka, R. E. ; Watwood, M. ; Ross, C., Environmental Pollution, 2002, 120, 191-200.

(3) Watwood, M. E. ; Kay-Shoemake, J. L., Journal of Soil Contamination, 2000, 9, 133147.

(4) Wong, J. Y. ; Velasco, A. ; Rajagopalan, P. ; Pham, Q., Langmuir, 2003, 19, 19081913.

(5) Brueggemeier, S. B. ; Kron, S. J. ; Palecek, S. P., Analytical Biochemistry, 2004, 329, 180-189.

(6) Furukawa, H., Journal of Molecular Structure, 2000, 554, 11-19.

(7) Kavanagh, G. M. ; Ross-Murphy, S. B., Progress in Polymer Science, 1998, 23, 533562.

(8) Okumura, Y. ; Ito, K., Advanced Materials, 2001, 13, 485-487.

(9) Starodoubtsev, S. G. ; Ryabova, A. A. ; Dembo, A. T. ; Dembo, K. A. ; Aliev, I. I. ; Wasserman, A. M. ; Khokhlov, A. R., Macromolecules, 2002, 35, 6362-6369.

(10) Haraguchi, K. ; Takehisa, T. ; Fan, S., Macromolecules, 2002, 35, 10162-10171.

(11) Haraguchi, K. ; Farnworth, R. ; Ohbayashi, A. ; Takehisa, T., Macromolecules, 2003, $36,5732-5741$.

(12) Gong, J. P. ; Katsuyama, Y. ; Kurokawa, T. ; Osada, Y., Advanced Materials, 2003, $15,1155-1158$.

(13) Na, Y.-H. ; Kurokawa, T. ; Katsuyama, Y. ; Tsukeshiba, H. ; Gong, J. P. ; Osada, Y. ; Okabe, S. ; Karino, T. ; Shibayama, M., Macromolecules, 2004, 37, 5370-5374.

(14) Nagaoka, S., Polymer Journal, 1989, 21, 847-850.

(15) Hatch, M. J. ; Dillon, J. A. ; Smith, H. B., Industrial and Engineering Chemistry, 1957, 49, 1812-1819.

(16) Kohut-Svelko, N. ; Reynaud, S. ; Dedryvere, R. ; Martinez, H. ; Gonbeau, D. ; Francois, J., Langmuir, 2005, 21, 1575-1583.

(17) Odian, G. Principles of Polymerization, 3rd ed; John Wiley \& Sons, New York: NY, 1991.

(18) Mayo, F. R. ; Lewis, F. M., Journal of American Chemical Society, 1944, 66, 1594 1601.

(19) Giz, A. ; Catalgil, G. I. Z. H. ; Alb, A. ; Brousseau, J. L. ; Reed, W. F., Macromolecules, 2001, 34, 1180-1191.

(20) Baselga, J. ; Llorente, M. A. ; Hernandez-Fuentes, I. ; Pierola, I. F., European Polymer Journal, 1989, 25, 477-480.

(21) Lindemann, B. ; Schroder, U. P. ; Oppermann, W., Macromolecules, 1997, 30, 40734077.

(22) Matsuo, E. S. ; Orkisz, M. ; Sun, S. T. ; Yong, L. ; Tanaka, T., Macromolecules, 1994, 27, 6791-6796.

(23) Takata, S. I. ; Norisuye, T. ; Shibayama, M., Macromolecules, 1999, 32, 3989-3993.

(24) Nossal, R., Macromolecules, 1985, 18, 49-54.

(25) Kizilay, M. Y. ; Okay, O., Macromolecules, 2003, 36, 6856-6862.

(26) Calvet, D. ; Wong, J. Y. ; Giasson, S., Macromolecules, 2004, 37, 7762-7771.

(27) Kerner, E., Proceedings of the Physical Society, 1956, 808-813.

(28) Bousmina, M., Rheologica Acta, 1999, 38, 73-83. 
(29) Léonardi, F. ; Majesté, J.-C. ; Allal, A. ; Marin, G., Journal of Rheology, 2000, 44, 665-692.

(30) Sawahata, K. ; Gong, J. P. ; Osada, Y., Macromolecular Rapid Communications, 1995, 16, 713-716.

(31) A. Katchalsky. Journal of Polymer Science, 1951, 7, 393-412. 


\section{Captions of Tables and Figures}

Table 1. Experimental conditions and kinetics parameters for the hydrogel polymerization

Table 2. Experimental conditions and kinetics parameters for the NPC hydrogel polymerization

Table 3. Experimental conditions and rheological results for the NPC hydrogel polymerization

Figure 1. ESEM images of PS latex particles

Figure 2. Spectra evolution of reaction mixture for the in situ PAM hydrogel formation in ${ }^{1} \mathrm{H}$ NMR probe

Figure 3. Am conversion $\mathrm{p}_{\mathrm{A}}$ as a function of $t$, at $\mathrm{T}=56^{\circ} \mathrm{C}$, including the first-order fit according to eq 15. Reaction designations are from Table 1. Inset: First-order monomer decay rates vs. $\left[\mathrm{I}_{2}\right]_{0}^{1 / 2}$ for $\% \mathrm{~B}=1$

Figure 4. Am conversion $\mathrm{p}_{\mathrm{A}}$ as a function of $t$, at various temperatures $\mathrm{T}$, including the firstorder fit according to eq 15. Reaction designations are from Table 1. Inset: first-order monomer decay rates in function of $1 / \mathrm{T}$

Figure 5. Initial decay rates of monomers A and B; 1- $\mathrm{p}_{\mathrm{A}}$ (full symbols) and 1- $\mathrm{p}_{\mathrm{B}}$ (empty symbols) versus time for runs 7 and 11

Figure 6. $\mathrm{Am}\left(\mathrm{p}_{\mathrm{A}}\right)$ and BisAm $\left(\mathrm{p}_{\mathrm{B}}\right)$ conversion as a function of $t$, at $\% \mathrm{~B}=9.3$ and $\mathrm{T}=56^{\circ} \mathrm{C}$ (run $\mathrm{C} 10$ ), including the first-order fit according to eq 15 and 16. Inset: determination of $\mathrm{r}_{\mathrm{A}}$ and $r_{B}$ using the ratio of $A$ and $B$ rate constants from eq 18. The values of $r_{A}$ and $r_{B}$ are 0.52 and 5.2, respectively

Figure 7. $\mathrm{W}_{\mathrm{bb}}(\bigcirc)$ and $<\mathrm{N}_{\mathrm{B}}>_{\mathrm{n}}(\boldsymbol{\Delta})$ versus total monomers conversion $p$ for Run C6

Figure 8. Mechanism of free-radical copolymerization in network formation

Figure 9. Am conversion $\mathrm{p}_{\mathrm{A}}$ as a function of $t$, in the presence of PS nanoparticles at $\mathrm{T}=$ $56^{\circ} \mathrm{C}$, including the first-order fit according to eq. 15 . Reaction designations are from Table 2

Figure 10. Evolution of elastic modulus as a function of the volume fraction of PS nanoparticles incorporated into the NPC gel. The line represents the Kerner's model and the points are experimental data

Figure 11. Time profile of tension $(\Delta \mathrm{V})$ (b) produced by compression of two hydrolyzed NPC gels (a): gel 1 without particles and deformation of $\Delta \mathrm{L}_{1} / \mathrm{L}$ and gel 2 with $26 \%$ of PS nanoparticles with a deformation of $\Delta \mathrm{L}_{2} / \mathrm{L}\left(\mathrm{L}=\mathrm{L}_{1,0}+\mathrm{L}_{2,0} ; \Delta \mathrm{L}_{1}=\mathrm{L}_{1,0}-\mathrm{L}_{1}\right.$ and $\left.\Delta \mathrm{L}_{2}=\mathrm{L}_{2,0}-\mathrm{L}_{2}\right)$ 
Table 1: Experimental conditions and kinetics parameters for the hydrogel polymerization

\begin{tabular}{|c|c|c|c|c|c|c|c|c|c|}
\hline Run & $\begin{array}{c}\mathbf{T} \\
\left({ }^{\circ} \mathrm{C}\right)\end{array}$ & $\% \mathbf{M}$ & $\begin{array}{c}{[\mathrm{A}]} \\
\left(\times 10^{1}\right) \\
\left(\mathrm{mol.L}^{-1}\right)\end{array}$ & $\% B$ & $\begin{array}{c}{[\mathrm{B}]} \\
\left(\times 10^{3}\right) \\
\left(\mathrm{mol}^{-L^{-1}}\right)\end{array}$ & $\%$ I & $\begin{array}{c}{\left[\mathrm{I}_{2}\right]_{0}} \\
\left(\times 10^{3}\right) \\
\left(\mathrm{mol}^{-L^{-1}}\right)\end{array}$ & $\begin{array}{c}\alpha_{A} \\
\left(\times 10^{3}\right) \\
\left(s^{-1}\right)\end{array}$ & $\begin{array}{c}\alpha_{B} \\
\left(\times 10^{3}\right) \\
\left(s^{-1}\right)\end{array}$ \\
\hline A1 & 56 & 7.1 & 9.8 & 1.0 & 9.2 & 0.13 & 0.33 & 2.94 & - \\
\hline A2 & 56 & 7.1 & 9.9 & 1.1 & 9.7 & 0.41 & 1.07 & 4.20 & - \\
\hline A3 & 56 & 7.1 & 9.9 & 1.1 & 9.7 & 0.98 & 2.55 & 6.01 & - \\
\hline A4 & 56 & 7.8 & 10.8 & 0.9 & 9.4 & 2.00 & 5.72 & 7.34 & - \\
\hline B1 & 36 & 7.1 & 9.8 & 1.0 & 9.0 & 1.0 & 2.58 & 0.62 & - \\
\hline B2 & 46 & 7.1 & 9.8 & 1.0 & 9.0 & 1.0 & 2.58 & 1.80 & - \\
\hline B3 & 50 & 7.1 & 9.8 & 1.0 & 9.0 & 1.0 & 2.58 & 2.15 & - \\
\hline B4 & 56 & 7.1 & 9.8 & 1.0 & 9.0 & 1.0 & 2.58 & 6.17 & - \\
\hline C5 & 56 & 7.6 & 10 & 4.7 & 46 & 0.046 & 0.13 & 2.08 & 4.05 \\
\hline C6 & 56 & 7.5 & 10 & 5.6 & 55 & 0.047 & 0.13 & 1.87 & 4.26 \\
\hline C7 & 56 & 7.6 & 9.9 & 6.6 & 65 & 0.046 & 0.13 & 2.08 & 4.45 \\
\hline C8 & 56 & 7.6 & 9.9 & 7.5 & 74 & 0.046 & 0.13 & 2.15 & 4.44 \\
\hline C9 & 56 & 7.7 & 9.9 & 8.2 & 82 & 0.046 & 0.13 & 1.46 & 3.67 \\
\hline C10 & 56 & 7.8 & 9.9 & 9.3 & 94 & 0.091 & 0.26 & 1.94 & 4.54 \\
\hline C11 & 56 & 5.1 & 5.2 & 27 & 178 & 0.29 & 0.54 & 1.52 & 4.88 \\
\hline
\end{tabular}


Table 2. Experimental conditions and kinetics parameters for the NPC hydrogel polymerization

\begin{tabular}{|c|c|c|c|c|c|c|c|c|}
\hline Run & $\begin{array}{c}\mathbf{T} \\
\left({ }^{\circ} \mathbf{C}\right)\end{array}$ & $\% \mathbf{M}$ & $\begin{array}{c}{[\mathrm{A}]} \\
\left(\times 10^{1}\right) \\
\left(\mathrm{mol}^{-L^{-1}}\right)\end{array}$ & $\% B$ & $\% \mathbf{I}$ & 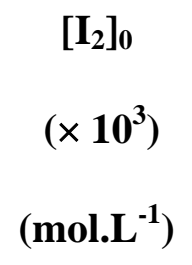 & $\phi(\%)$ & $\begin{array}{c}\alpha_{\mathrm{A}} \\
\left(\times 10^{3}\right) \\
\left(\mathrm{s}^{-1}\right)\end{array}$ \\
\hline D1 & 56 & 7.1 & 9.9 & 1.1 & 0.98 & 2.55 & O no surfactant & 6.01 \\
\hline D2 & 56 & 7.2 & 10 & 1.0 & 0.97 & 2.57 & 0.31 & 4.37 \\
\hline D3 & 56 & 7.0 & 9.7 & 1.0 & 1.06 & 2.72 & 0.72 & 3.41 \\
\hline D4 & 56 & 7.2 & 10 & 1.0 & 1.05 & 2.77 & 1.83 & 3.39 \\
\hline D5 & 56 & 4.3 & 6.0 & 1.0 & 0.99 & 1.56 & 12.6 & 0.37 \\
\hline D6 & 56 & 4.2 & 6.0 & $\mathbf{0}$ & 1.16 & 1.81 & 13.1 & 0.38 \\
\hline D7 & 56 & 4.5 & 6.2 & 1.0 & 1.00 & 1.66 & O with surfactants ${ }^{\mathrm{a}}$ & 3.58 \\
\hline D8 & 56 & 4.5 & 6.2 & 1.2 & 1.25 & 2.08 & $\mathbf{0}$ with surfactants ${ }^{\mathrm{b}}$ & 3.74 \\
\hline D9 & 56 & 4.4 & 6.1 & 1.1 & 0.98 & 1.54 & O no surfactant & 3.17 \\
\hline
\end{tabular}


Table 3. Experimental conditions and rheological results for the NPC hydrogel polymerization

\begin{tabular}{|c|c|c|c|c|c|c|c|}
\hline Run & $\% \mathbf{M}$ & $\begin{array}{c}{[\mathrm{A}]} \\
\left(\times \mathbf{1 0}^{1}\right) \\
\left(\mathrm{mol.L}^{-1}\right)\end{array}$ & $\% B$ & $\begin{array}{c}{[\mathrm{B}]} \\
\left(\times 10^{3}\right) \\
\left(\mathrm{mol.L}^{-1}\right)\end{array}$ & $\begin{array}{c}{\left[\mathrm{I}_{2}\right]_{0}} \\
\left(\times 10^{3}\right) \\
\left(\mathrm{mol}^{3} \mathrm{~L}^{-1}\right)\end{array}$ & $\phi(\%)$ & $G^{\prime}(P a)$ \\
\hline G1 & 7.1 & 9.9 & 1.0 & 9.2 & 2.6 & 0 & 2200 \\
\hline G2 & 7.1 & 9.9 & 0.9 & 8.1 & 2.8 & 0.32 & 2300 \\
\hline G3 & 7.1 & 9.9 & 0.8 & 7.0 & 2.8 & 1.81 & 2100 \\
\hline G4 & 7.0 & 9.8 & 0.8 & 7.1 & 3.5 & 15.1 & 10800 \\
\hline G5 & 7.3 & 10.2 & 0.8 & 7.1 & 3.4 & 20.3 & 19000 \\
\hline G6 & 7.4 & 10.3 & 0.8 & 7.2 & 3.4 & 26.0 & 36100 \\
\hline
\end{tabular}


Figure 1. ESEM images of PS latex particles

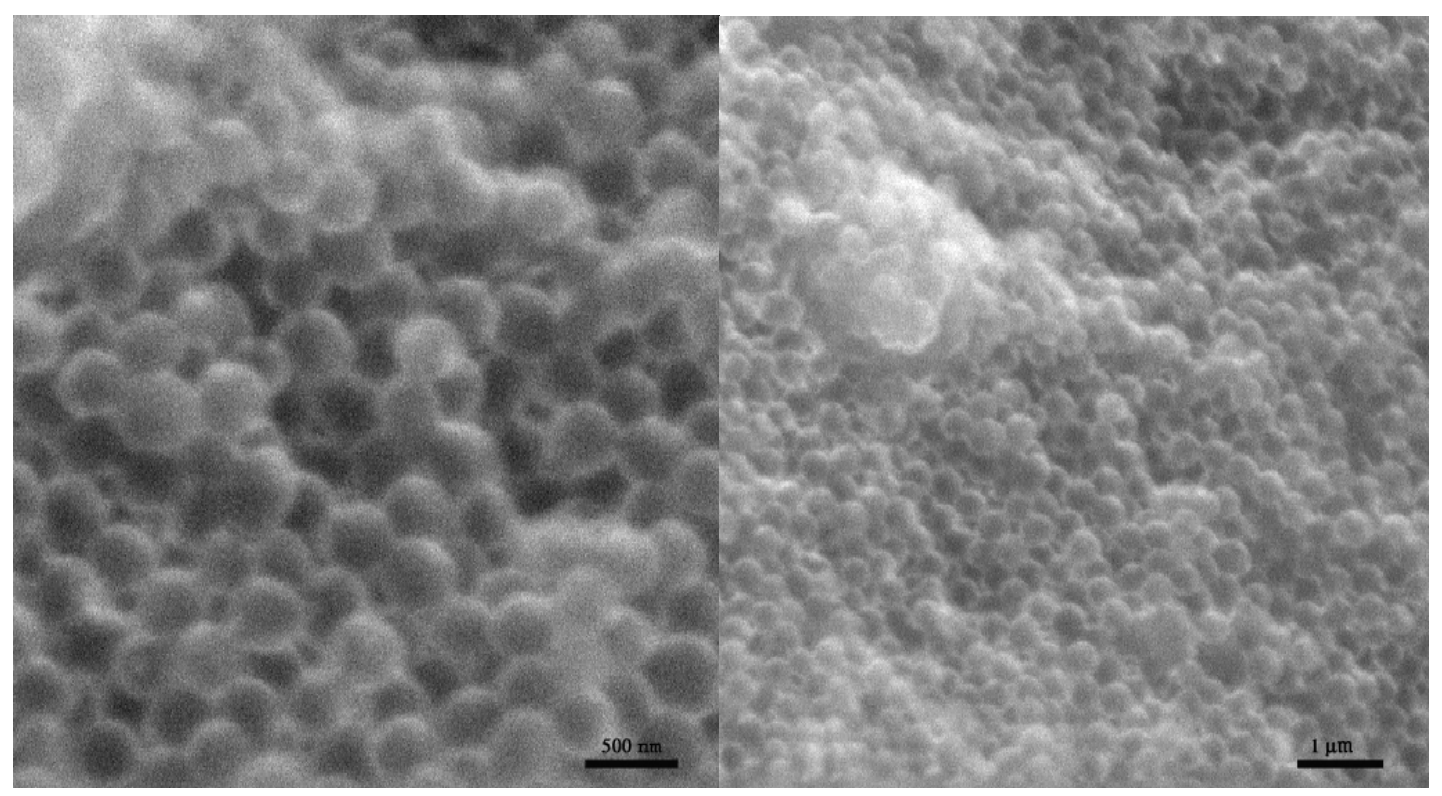


Figure 2. Spectra evolution of reaction mixture for the in situ PAM hydrogel formation in ${ }^{1} \mathrm{H}-$ NMR probe

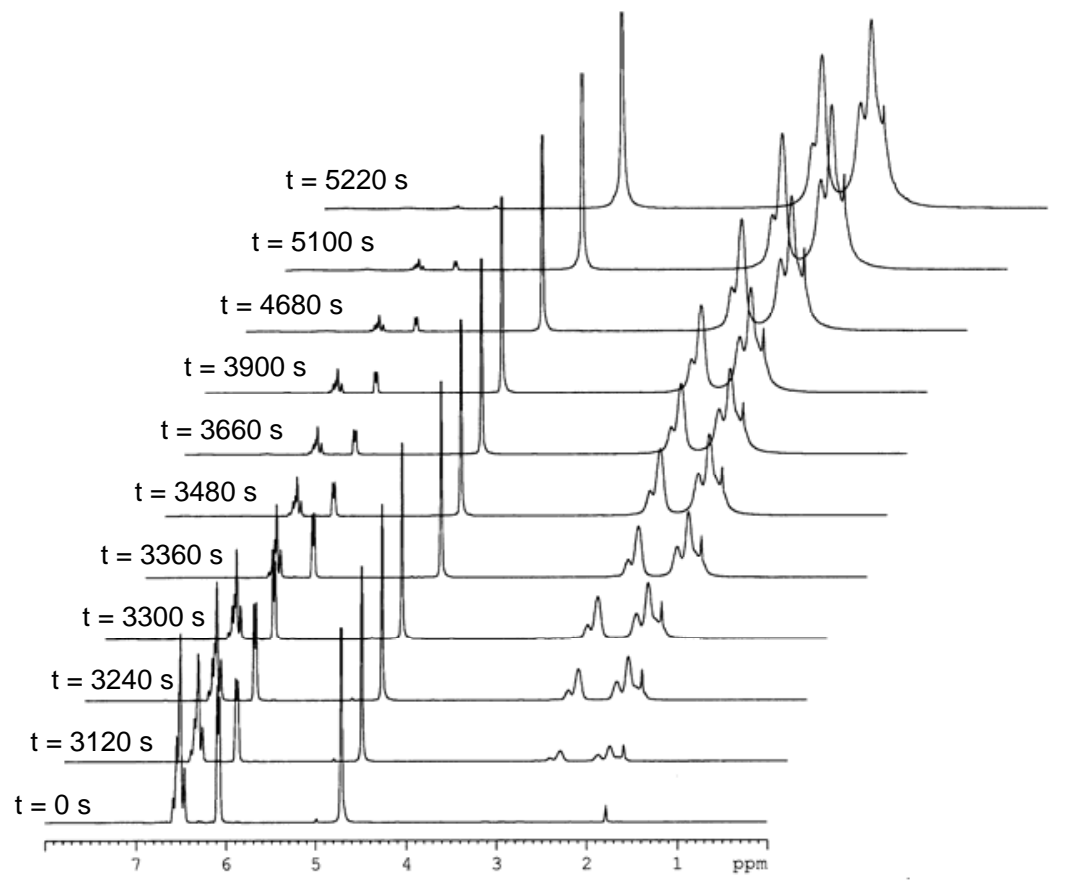


Figure 3. Am conversion $\mathrm{p}_{\mathrm{A}}$ as a function of $t$, at $\mathrm{T}=56^{\circ} \mathrm{C}$, including the first-order fit according to eq 15. Reaction designations are from Table 1. Inset: First-order monomer decay rates vs. $\left[\mathrm{I}_{2}\right]_{0}^{1 / 2}$ for $\% \mathrm{~B}=1$

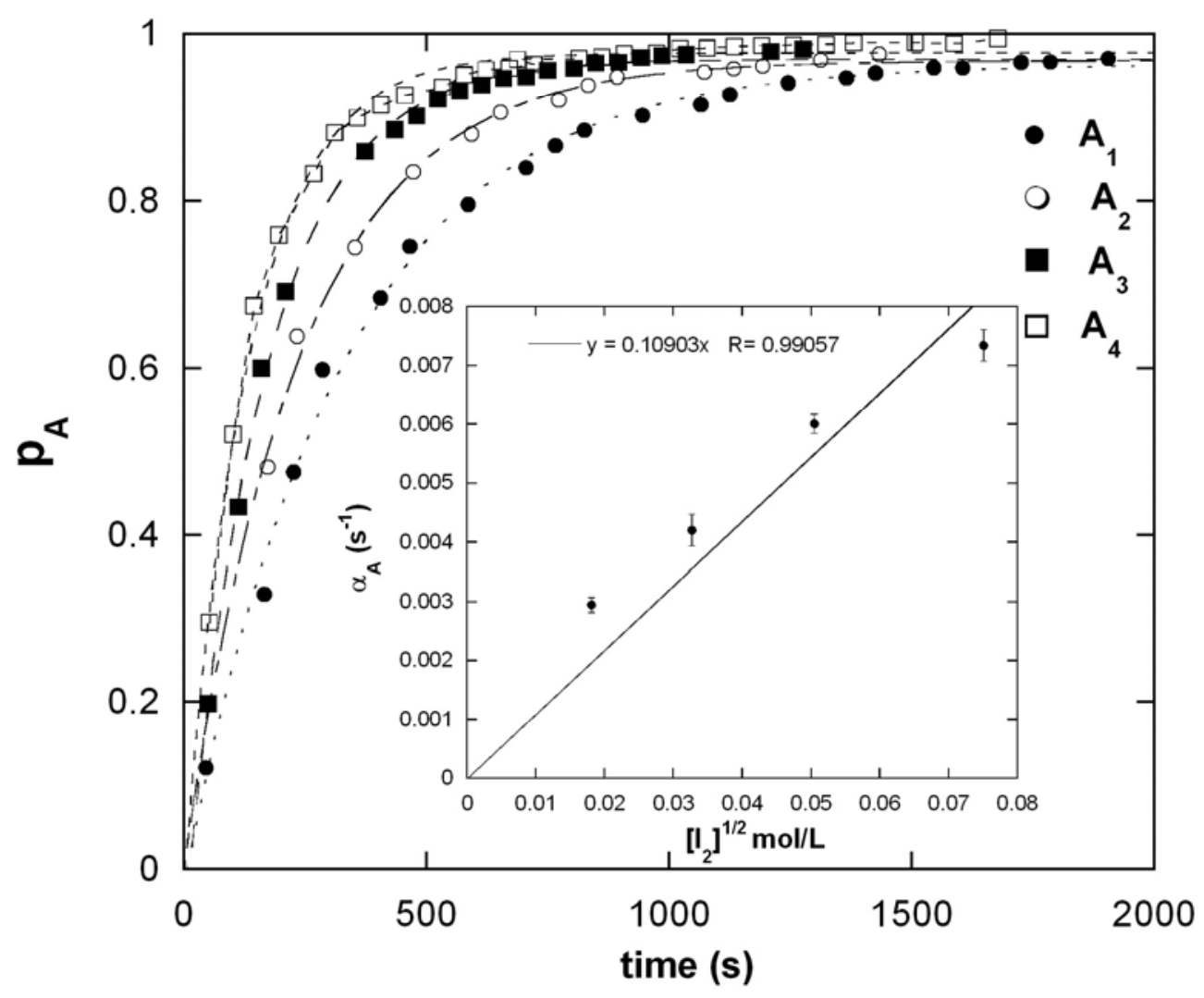


Figure 4. Am conversion $\mathrm{p}_{\mathrm{A}}$ as a function of $t$, at various temperatures $\mathrm{T}$, including the firstorder fit according to eq 15. Reaction designations are from Table 1. Inset: first-order monomer decay rates in function of $1 / \mathrm{T}$

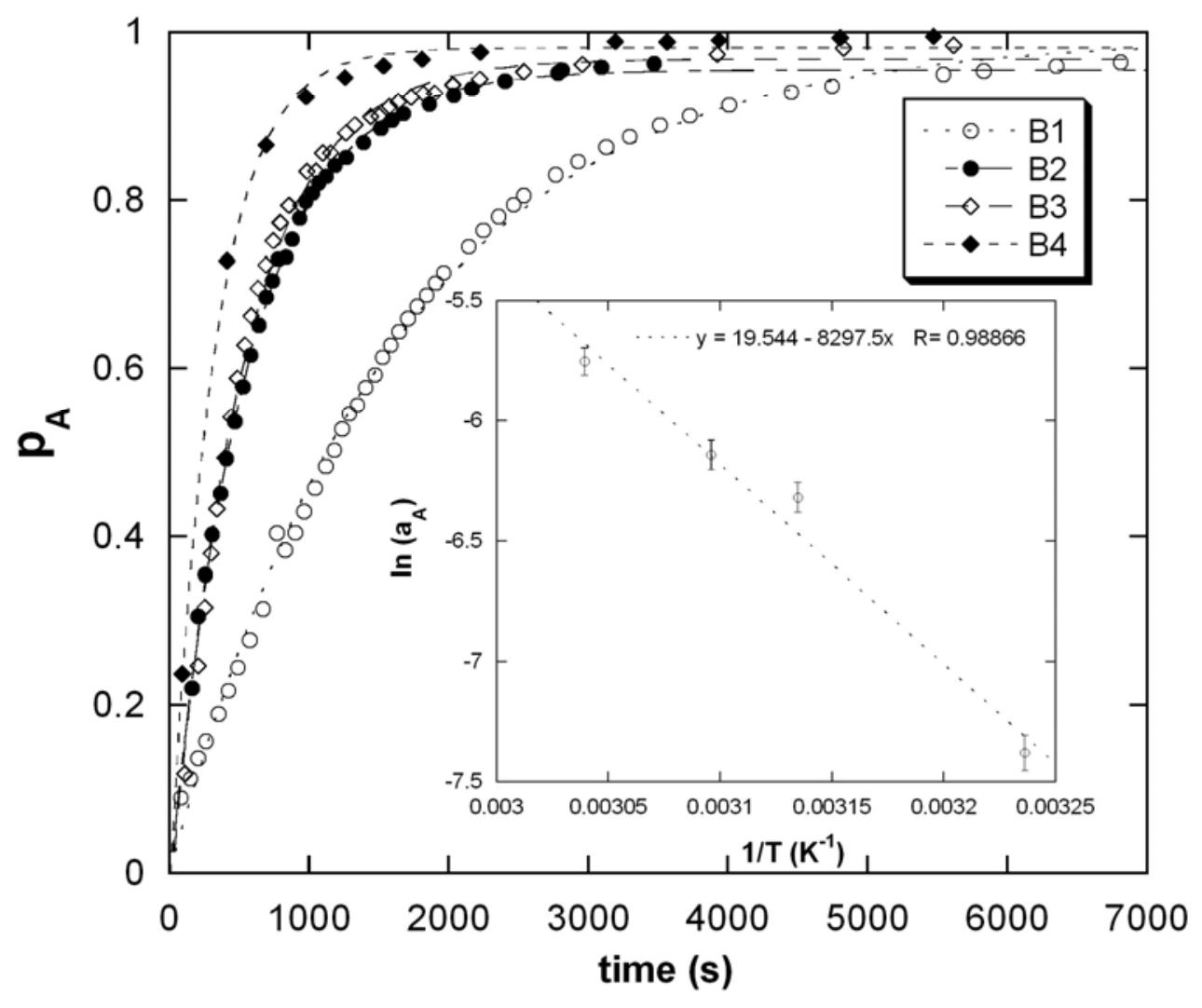


Figure 5. Initial decay rates of monomers $A$ and $B$; 1- $\mathrm{p}_{\mathrm{A}}$ (full symbols) and 1- $\mathrm{p}_{\mathrm{B}}$ (empty symbols) versus time for runs 7 and 11

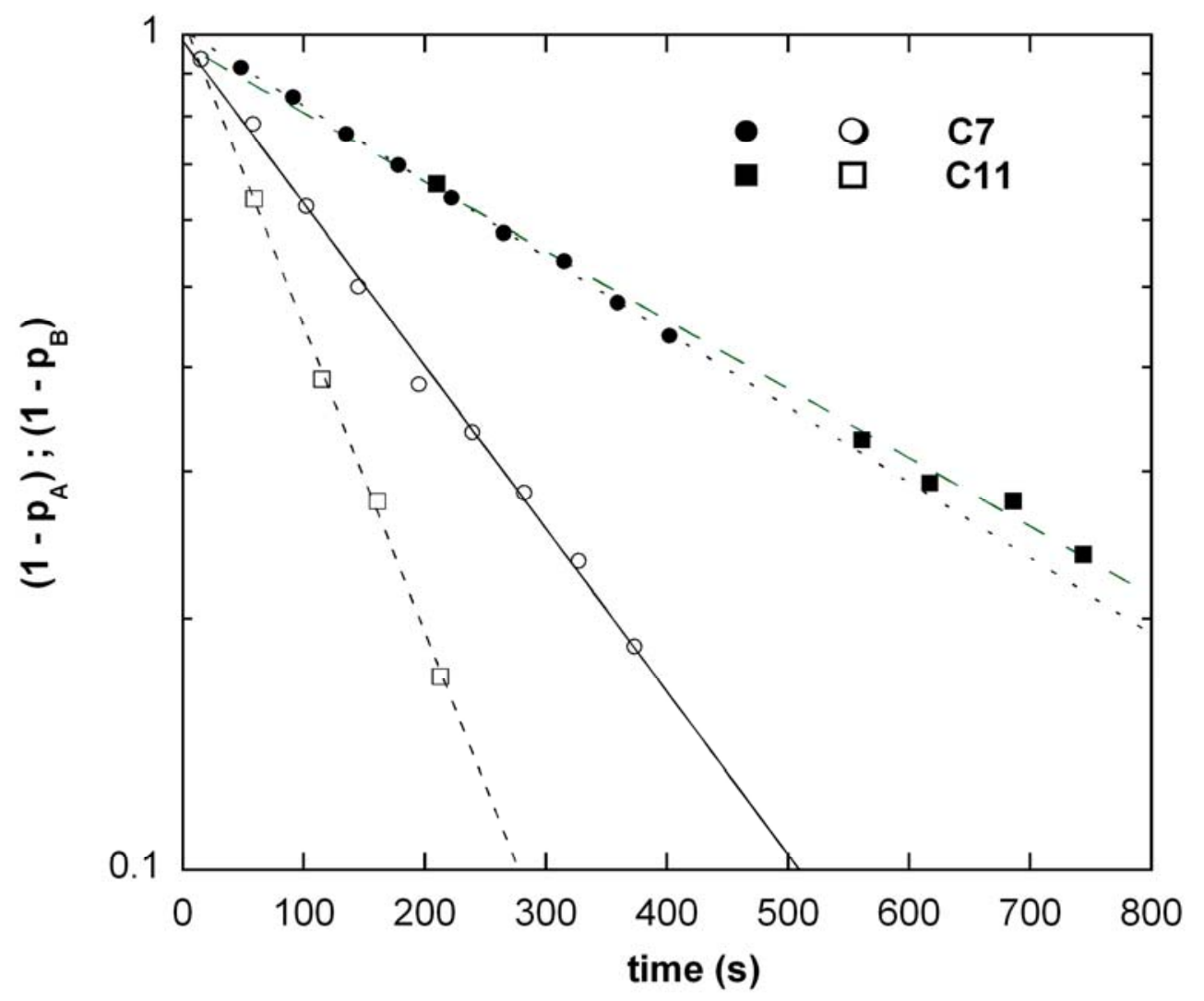


Figure 6. $\mathrm{Am}\left(\mathrm{p}_{\mathrm{A}}\right)$ and BisAm $\left(\mathrm{p}_{\mathrm{B}}\right)$ conversion as a function of $t$, at $\% \mathrm{~B}=9.3$ and $\mathrm{T}=56^{\circ} \mathrm{C}$ (run C10), including the first-order fit according to eq 15 and 16. Inset: determination of $\mathrm{r}_{\mathrm{A}}$ and $r_{B}$ using the ratio of $A$ and $B$ rate constants from eq 18. The values of $r_{A}$ and $r_{B}$ are 0.52 and 5.2, respectively

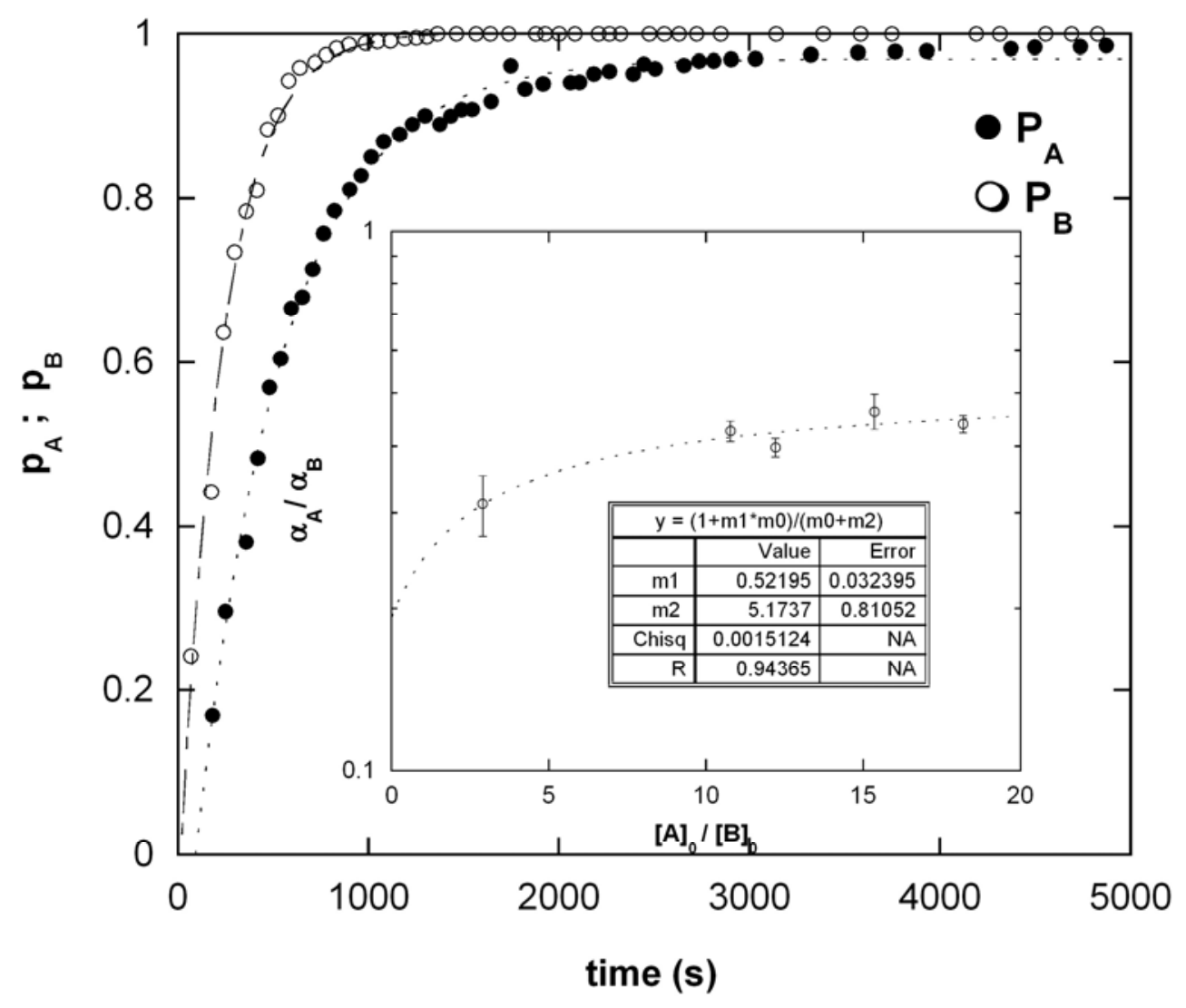


Figure 7. $\mathrm{W}_{\mathrm{bb}}(\bigcirc)$ and $<\mathrm{N}_{\mathrm{B}}>_{\mathrm{n}}(\boldsymbol{\Delta})$ versus total monomers conversion $p$ for Run C6

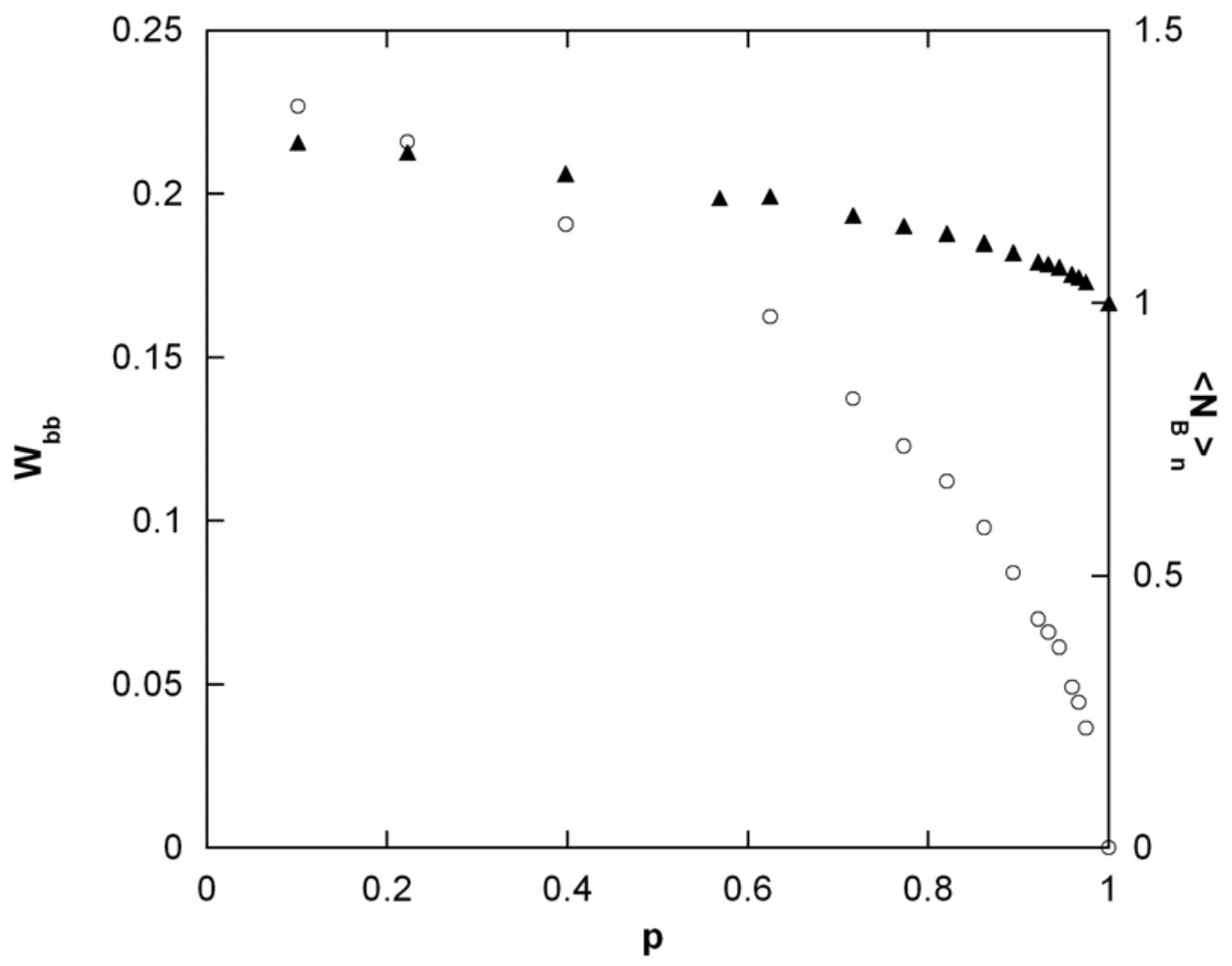


Figure 8. Mechanism of free-radical copolymerization in network formation

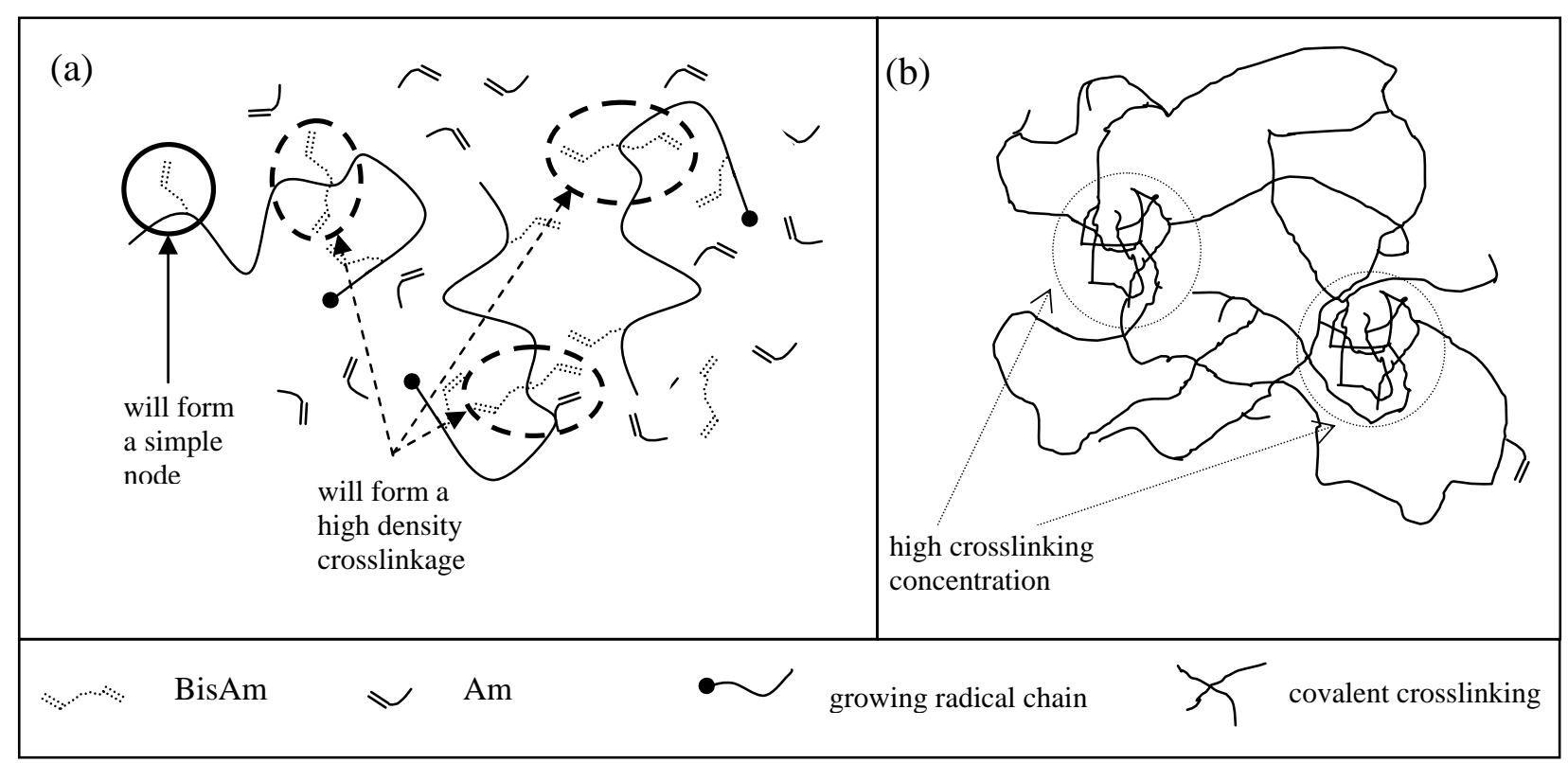


Figure 9. Am conversion $\mathrm{p}_{\mathrm{A}}$ as a function of $t$, in the presence of PS nanoparticles at $\mathrm{T}=$ $56^{\circ} \mathrm{C}$, including the first-order fit according to eq. 15 . Reaction designations are from Table 2

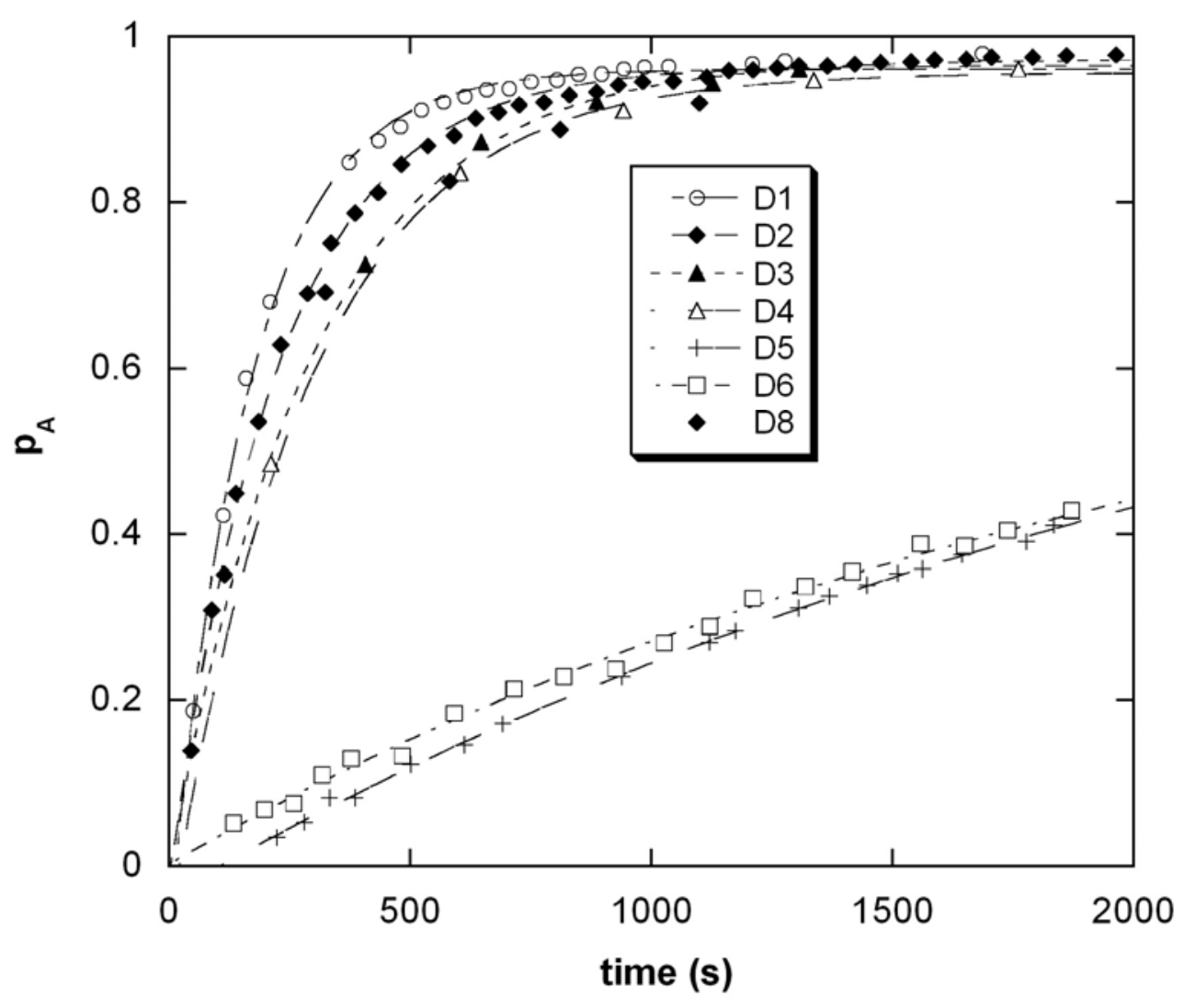


Figure 10. Evolution of elastic modulus as a function of the volume fraction of PS nanoparticles incorporated into the NPC gel. The line represents the Kerner's model and the points are experimental data




Figure 11. Time profile of tension $(\Delta \mathrm{V})$ (b) produced by compression of two hydrolyzed NPC gels (a): gel 1 without particles and deformation of $\Delta \mathrm{L}_{1} / \mathrm{L}$ and gel 2 with $26 \%$ of PS nanoparticles with a deformation of $\Delta \mathrm{L}_{2} / \mathrm{L}\left(\mathrm{L}=\mathrm{L}_{1,0}+\mathrm{L}_{2,0} ; \Delta \mathrm{L}_{1}=\mathrm{L}_{1,0}-\mathrm{L}_{1}\right.$ and $\left.\Delta \mathrm{L}_{2}=\mathrm{L}_{2,0}-\mathrm{L}_{2}\right)$

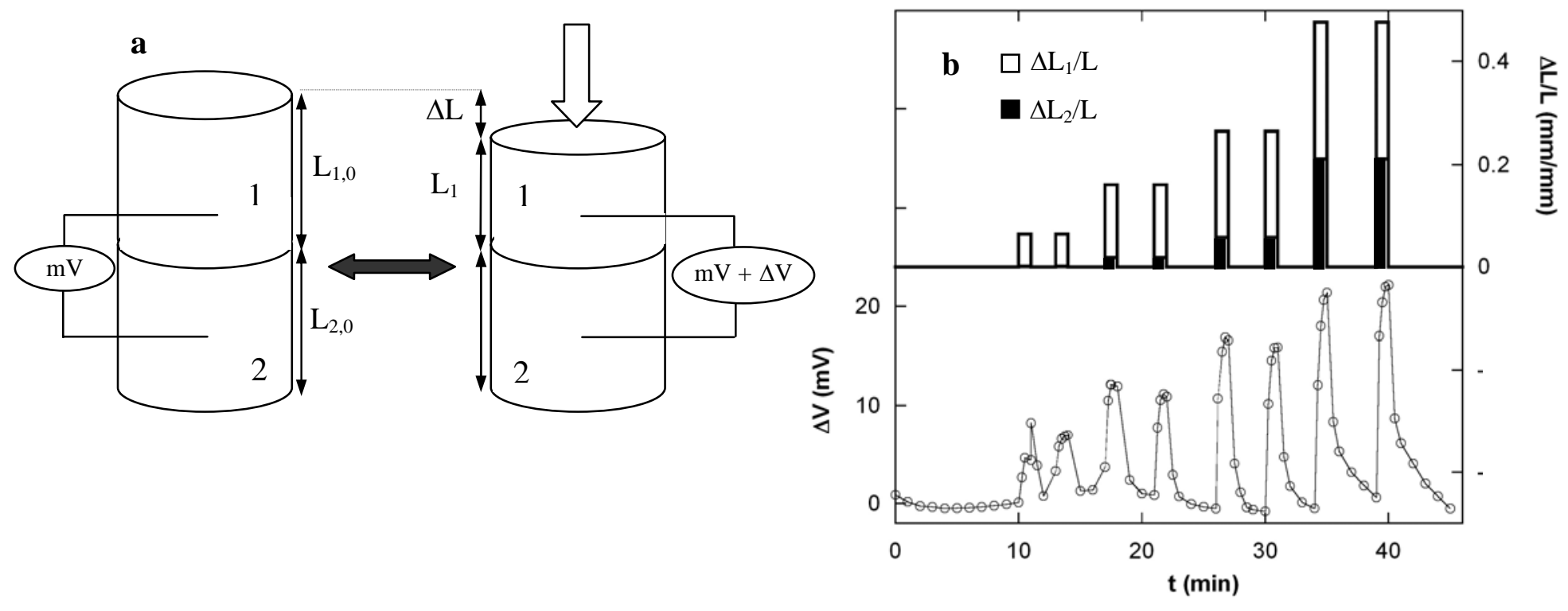

